University of Nebraska - Lincoln

DigitalCommons@University of Nebraska - Lincoln

Sociology Department, Faculty Publications

Sociology, Department of

2008

\title{
Violence Against Separated, Divorced, and Married Women in Canada, 2004
}

Douglas A. Brownridge

University of Manitoba

Diane Hiebert-Murphy

University of Manitoba, Winnipeg, Canada

Janice Ristock

University of Manitoba, Winnipeg, Canada

Ko Ling Chan

University of Hong Kong

Kimberly A. Tyler

University of Nebraska-Lincoln, kim@ktresearch.net

See next page for additional authors

Follow this and additional works at: https://digitalcommons.unl.edu/sociologyfacpub

Part of the Sociology Commons

Brownridge, Douglas A.; Hiebert-Murphy, Diane; Ristock, Janice; Ling Chan, Ko; Tyler, Kimberly A.; and Santos, Suzy C., "Violence Against Separated, Divorced, and Married Women in Canada, 2004" (2008). Sociology Department, Faculty Publications. 42.

https://digitalcommons.unl.edu/sociologyfacpub/42

This Article is brought to you for free and open access by the Sociology, Department of at DigitalCommons@University of Nebraska - Lincoln. It has been accepted for inclusion in Sociology Department, Faculty Publications by an authorized administrator of DigitalCommons@University of Nebraska - Lincoln. 


\section{Authors}

Douglas A. Brownridge, Diane Hiebert-Murphy, Janice Ristock, Ko Ling Chan, Kimberly A. Tyler, and Suzy C. Santos 


\title{
Violence Against Separated, Divorced, and Married Women in Canada, 2004
}

\author{
Douglas A. Brownridge \\ Diane Hiebert-Murphy \\ Janice Ristock \\ Ko Ling Chan \\ Agnes Tiwari \\ Kimberly A. Tyler \\ Susy C. Santos
}

\begin{abstract}
The purpose of this study was to examine violence against separated, divorced, and married women using Statistics Canada's 2004 General Social Survey. Based on a subsample of 6,716 heterosexual
\end{abstract}

Douglas A. Brownridge, PhD, is Associate Professor, Department of Family Social Sciences, and Adjunct Professor, Arthur V. Mauro Centre for Peace and Justice, University of Manitoba, Winnipeg, Canada, and Honorary Professor, University of Hong Kong.

Diane Hiebert-Murphy, $\mathrm{PhD}$, is Associate Professor, Faculty of Social Work, and Janice Ristock, PhD, is Professor, Women's Studies Program, University of Manitoba, Winnipeg, Canada.

Ko Ling Chan, PhD, is Assistant Professor, Department of Social Work and Social Administration, and Agnes Tiwari is Associate Professor, Department of Nursing, University of Hong Kong.

Kimberly A. Tyler, PhD, is Associate Professor, Department of Sociology, University of Nebraska-Lincoln.

Susy C. Santos is a PhD candidate in the Departments of Psychology and French, Spanish \& Italian, and Faculty of Medicine, University of Manitoba, Winnipeg, Canada.

Address correspondence to: Douglas A. Brownridge, Department of Family Social Sciences, 35 Chancellor's Circle, University of Manitoba, Winnipeg, MB, Canada R3T2N2 (E-mail: Douglas_Brownridge@umanitoba.ca).

Journal of Divorce \& Remarriage, Vol. 49(3/4) 2008

Available online at http://www.haworthpress.com

(C) 2008 by The Haworth Press. All rights reserved.

doi: $10.1080 / 10502550802222121$ 
women (429 separated; 614 divorced; 5,673 married), available risk markers were examined in the context of a nested ecological framework. Consistent with past research, the results indicated that there may be differences in the dynamics of violence across the 3 groups. Separated women reported 7 times the prevalence of violence and divorced women reported twice the prevalence of violence than married women in the year prior to the study. Young age was an important predictor of violence for separated and divorced women. Unemployment and the presence of children of the ex-partner were important predictors for divorced women. Patriarchal domineering and sexually proprietary behaviors were strong predictors of violence for married women. The results suggested the possibility that motives for postseparation violence tend to differ depending on whether one is separated or divorced. Future research is warranted to uncover these potentially differing dynamics of risk.

KEYWORDS. Violence, abuse, separation, divorce

The majority of research on intimate partner violence against women has focused on occurrences of violence within intact unions (Anderson \& Saunders, 2003), with relatively few studies examining violence against women postseparation (McMurray, Froyland, Bell, \& Curnow, 2000). Over the past three decades research on violence against women postseparation has slowly accumulated. Overall, these studies have indicated that: (a) compared to married women, separated women face an elevated risk for both lethal and nonlethal violence and divorced women face an elevated risk of nonlethal violence; and (b) the extent to which the risk for nonlethal violence is elevated is greater for separated than for divorced women (cf. Brownridge, 2006). These findings suggested the possibility that the dynamics of risk for violence differ for separated, divorced, and married women. One way in which to shed light on the potentially differing dynamics of violence for separated, divorced, and married women is to compare these groups of women not only in terms of their prevalence of violence, but also with respect to the operation of risk markers for violence. As such, the purpose of the this article was to extend a previous analysis (Brownridge et al., 2008 ) of the potentially differing dynamics of violence against separated and divorced women by their ex-husbands and violence against married women by their current husbands using a more

This research was supported by a Standard Research Grant from the Social Sciences and Humanities Research Council of Canada (SSHRC). 
recently collected nationally representative sample of Canada, Statistics Canada's 2004 General Social Survey.

\section{A NESTED ECOLOGICAL FRAMEWORK FOR EXAMINING RISK MARKERS OF VIOLENCE}

Past research has identified a number of potential risk markers for postseparation violence spanning all levels of the postseparation environment, which suggested the utility of organizing these risk markers within a nested ecological framework (Brownridge, 2006). What follows identifies risk markers that were available in the data employed in this study and how they were expected to be related to violence based on their application in the nested ecological framework.

\section{Macrosystem}

The macrosystem includes the cultural values and attitudes that foster violence. Patriarchy has been identified as playing an important role in violence both in intact unions and postseparation. Within marriage, men may use violence to exert their position of dominance over their partner (Yllö \& Straus, 1990). Patriarchy may also contribute to postseparation violence through perpetuation of the notion that men are entitled to an ongoing relationship and the expectation of female obedience, loyalty, and dependence (Hardesty, 2002). Because most marriages are ended by women (Hewitt, Baxter, \& Western, 2005), men may see this as a challenge to their patriarchal authority. Thus, separated and divorced men may use violence in an attempt to reclaim their rights and their role of dominance over their former partner.

\section{Microsystem}

The microsystem consists of the family or immediate setting in which violence occurs.

\section{Female Independence}

Resource theory suggests that the powerful will dominate the less powerful (Blood \& Wolfe, 1960). Men have traditionally held more power than women because of their greater income, social standing outside the family, and knowledge and expertise due to their employment (Johnson, 1996). Goode (1971) added a central proposition to resource theory in 
which it was argued that it may be men who do not have access to conventional resources who use violence as the "ultimate resource" to keep their partners in line. It is also possible that among married women those who are more independent may be more likely to be victims of violence because this may be the only resource these women's partners have with which to dominate them. Abusive men have been shown to use violence in an attempt to prevent their partner from acting independently (Kurz, 1996). Hence, male partner violence against women may vary by the degree of independence of the woman such that the more independent the woman is, for example, in terms of the possession of education and employment resources, the more likely she may be to experience violence. With respect to women who leave their partners, they are clearly acting independently, suggesting that they may be more likely than their counterparts who would like to leave to possess resources that help them to be independent. Indeed, female dependence functions to keep women within marriage (Dutton \& Painter, 1993). If women who leave their partners are more likely to possess resources that allow them to be independent, this may be a particularly relevant risk marker for violence postseparation.

\section{Children}

An association between the presence of children and violence in intact unions is often attributed to stress (Brownridge \& Halli, 2002). In a postseparation context, the presence of children has been identified as potentially being both a protective and a risk factor, although most research has focused on the latter (Brownridge, 2006). The presence of children may be protective if men refrain from violence to prevent the denial of future access to their children. On the other hand, if men are late in their support payments, a denial of access in retaliation may lead them to become violent. Access may also contribute to violence by virtue of increased contact and therefore opportunity for violence. Resentment over child support payments may also lead to postseparation violence. The trend toward joint custody orders, which were awarded for $41.8 \%$ of dependents in Canadian divorce proceedings in 2002 (Statistics Canada, 2004), may contribute to postseparation violence because both parents are required to interact in decision making regarding the child(ren).

\section{Ontogenic Level}

The ontogenic level comprises the individual's development and, as a result, what people bring to the other levels based on their development. 
Age

Women who are young are at the greatest risk for violence in general (Johnson, 1996). The average age at marriage in Canada is in the mid- to late 20s and the peak union duration for divorce to occur in Canada is during the fourth year of the marriage (Statistics Canada, 2004). Thus, youth may be particularly related to violence postseparation.

\section{Aboriginal Status}

Aboriginal women living in marital or common-law unions in Canada have been shown to be at elevated risk for partner violence (Brownridge, 2003). Although established risk markers of violence accounted for a sizable proportion of Aboriginal women's elevated risk, controlling for these risk markers, Aboriginal women still had significantly elevated odds of violence in the 5-year period prior to the survey compared to non-Aboriginal women. Among separated women in Canada, Aboriginal women have been shown to have a significantly higher annual prevalence of violence by their ex-partner compared to non-Aboriginal women (Spiwak \& Brownridge, 2005), but this study did not compare separated women to divorced and married women.

\section{Sexual Proprietariness}

It can be argued that an individual's developmental history is strongly linked to his or her attitudes and behavior. Men who hold attitudes that lead them to behave in a sexually proprietary way toward their partner have clearly learned at some point that this kind of behavior is acceptable. According to Wilson and Daly (1993), "a sexually proprietary masculine psychology ... treats wives as valued sexual and reproductive commodities that might be usurped by rivals" (p. 13). Sexual proprietariness has been associated with marital violence (Brownridge, 2002; Wilson \& Daly, 1998). In terms of postseparation violence, it has been argued that, after a woman's physical or psychological exit from a relationship, sexually proprietary men "feel deprived of the power of ownership and thus feel justified in trying to take back their possession(s) by whatever means they can, including physical force" (McMurray, 1997, p. 551). Research has suggested support for a connection between sexual proprietariness and postseparation violence in terms of both sexual jealousy (Fleury, Sullivan, \& Bybee, 2000; Hotton, 2001; Johnson \& Hotton, 2003) and possessiveness (Rasche, 1993). 


\section{METHODS}

\section{The Data Set}

The data employed in this study were from Cycle 18 of Statistics Canada's General Social Survey (GSS). ${ }^{1}$ Cycle 18 of the GSS was administered in 2004 and resulted in a random sample of 23,766 men and women 15 years of age or older. Because the study investigated male partner violence against women with current or former partners, ${ }^{2}$ the subsamples of heterosexual women ${ }^{3}$ who were either married or separated or divorced included 6,716 women (429 separated; 614 divorced; 5,673 married). ${ }^{4}$

\section{Measurement}

Independent Variables

Patriarchal dominance was measured with an item that asked the respondent if her ex- or current partner prevented her from knowing about or having access to the family income, even if she asked. ${ }^{5}$ Education referred to the respondent's education in years. Employment was measured with a question that referred to whether the main activity in the 12 months prior to the interview was working at a paid job or business (employed) or looking for work, caring for children, or housework (unemployed). The presence of children was measured by the respondent's report of whether or not children aged 0 to 14 were residing in the household. For ex-partners, this variable included only children of the ex-partner. Age referred to the respondent's age at the time of the interview. Aboriginal status was measured in terms of whether the respondent identified her cultural or racial background as being Aboriginal (North American Indian, Métis, or Inuit) or some other background (non-Aboriginal). The measure of sexual jealousy was based on a question asking the respondent if her ex- or current partner was jealous and did not want her to talk to other men. Possessiveness was measured with an item asking the respondent if her ex- or current partner demanded to know who she was with and where she was at all times.

\section{Dependent Variable}

Violence was measured with 10 behavioral items from a modified version of the Conflict Tactics Scales (CTS; Statistics Canada, 2005; Straus, 1979). Male partner violence against women was defined as acts of physical 
assault (being pushed, grabbed, or shoved in a way that could hurt; being slapped; being choked; having something thrown that could hurt; being hit with something that could hurt; being threatened with or having a knife or gun used; being kicked, bitten, or hit with a fist; being beaten), physical threat (being threatened to be hit with a fist or anything else that could hurt), and sexual assault (being forced into any sexual activity by being threatened, held down, or hurt in some way) perpetrated by a woman's current or former partner within the year prior to the interview. If respondents reported having experienced any of the aforementioned forms of violence within the year prior to the interview they were coded as having experienced violence.

\section{Methods of Data Analysis}

The analysis was conducted in two stages. To document the prevalence of violence among separated, divorced, and married women and investigate risk markers, the first stage consisted of descriptive analyses in which prevalence rates were calculated and bivariate relationships were examined using cross-tabulations with chi-square tests of significance. In the second stage, more elaborate analyses were conducted using a multivariate statistical technique. These analyses allowed an assessment of the impact of the independent variables on violence for separated, divorced, and married women. As well, these analyses, combined with $t$ tests to examine differences in odds ratios, allowed comparisons of the operation of these risk markers in the prediction of violence against separated, divorced, and married women. The multivariate technique used for this purpose was logistic multiple regression. Logistic regression is an appropriate technique for predicting a dichotomous dependent variable from a set of independent variables. This technique also has a very simple interpretation. For a given variable it provides a ratio of the odds of violence occurring. If the value of the odds is greater than one the variable is positively related to violence. If it is less than one the variable is negatively related to violence.

\section{RESULTS}

\section{Descriptive Analysis}

Separated women reported by far the highest prevalence of violence $(8.0 \%)$, followed by divorced women $(2.6 \%)$ and then married women ( $1.1 \%$; results not shown). 
Independent Variables by Separated, Divorced, and Married Status

Table 1 contains the means and percentages of the independent variables for separated, divorced, and married women. As shown in Table 1, separated and divorced women were much more likely to report that their ex-partner dominated them by preventing access to the family income than were married women to have a husband who behaved in such a manner. All three groups of women had similar education levels with a mean of about 13 years. Divorced women were most likely to be employed,

TABLE 1. Means and percentages of independent variables for separated, divorced, and married women

\begin{tabular}{|c|c|c|c|c|c|c|}
\hline \multirow[t]{2}{*}{ Independent Variables } & \multicolumn{2}{|c|}{$N=429$} & \multicolumn{2}{|c|}{$N=614$} & \multicolumn{2}{|c|}{$N=5,673$} \\
\hline & Separated & $n$ & Divorced & $n$ & Married & $n$ \\
\hline \multicolumn{7}{|l|}{$\begin{array}{l}\text { Macrosystem } \\
\text { Ex- or partner's } \\
\text { patriarchal } \\
\text { dominance }\end{array}$} \\
\hline Yes & 19.3 & 82 & 18.2 & 111 & 0.9 & 51 \\
\hline No & 80.7 & 341 & 81.8 & 498 & 99.1 & 5,521 \\
\hline \multicolumn{7}{|l|}{ Microsystem } \\
\hline $\begin{array}{l}\text { Education } \\
\text { Employment }\end{array}$ & 13.1 & 426 & 13.6 & 610 & 13.1 & 5,560 \\
\hline Employed & 84.2 & 298 & 90.1 & 443 & 71.7 & 3,081 \\
\hline Unemployed & 15.8 & 56 & 9.9 & 48 & 28.3 & 1,218 \\
\hline \multicolumn{7}{|l|}{ Children $<15$} \\
\hline Yes & 56.7 & 243 & 40.1 & 246 & 35.7 & 2,023 \\
\hline No & 43.3 & 185 & 59.9 & 368 & 64.3 & 3,650 \\
\hline \multicolumn{7}{|l|}{ Ontogenic } \\
\hline Age & 44.5 & 429 & 49.4 & 614 & 48.8 & 5,673 \\
\hline \multicolumn{7}{|l|}{ Aboriginal status } \\
\hline Aboriginal & 5.0 & 21 & 3.6 & 22 & 1.6 & 88 \\
\hline Non-Aboriginal & 95.0 & 403 & 96.4 & 584 & 98.4 & 5,427 \\
\hline \multicolumn{7}{|l|}{$\begin{array}{l}\text { Ex-or partner's } \\
\text { jealousy }\end{array}$} \\
\hline Yes & 31.2 & 132 & 30.7 & 187 & 2.4 & 132 \\
\hline No & 68.8 & 291 & 69.3 & 422 & 97.6 & 5,443 \\
\hline \multicolumn{7}{|l|}{$\begin{array}{l}\text { Ex- or partner's } \\
\text { possessiveness }\end{array}$} \\
\hline Yes & 26.2 & 111 & 24.9 & 152 & 2.4 & 134 \\
\hline No & 73.8 & 311 & 75.1 & 457 & 97.6 & 5,441 \\
\hline
\end{tabular}


followed by separated and married women. Separated women were the most likely to have children residing in the household. Divorced and married women had about the same mean age of 49 years, and separated women were younger with an average age of 45 years. Separated women were more likely than divorced or married women to be Aboriginal. Separated and divorced women were much more likely to have had a partner who was sexually proprietary, both in terms of jealousy and possessiveness, compared to married women's reports of their current husband's behaviors.

\section{Violence by Independent Variables for Separated, Divorced, and Married Women}

Table 2 provides the results of the cross-tabulations of the independent variables by the 1-year prevalence of violence for separated, divorced, and married women. As shown in Table 2, separated women whose ex-partners engaged in patriarchal domineering behavior were about three times more likely to report violence by their ex-partner in the previous year. Divorced women with such an ex-partner were about five times more likely to report having experienced violence. Married women with a partner who engaged in patriarchal domination reported violence at a rate 22 times that of their counterparts who did not have a partner that behaved in a patriarchal domineering manner. No significant association was found between education and violence for separated women. Although there was a significant difference for married women, there did not appear to be a substantive association between education and violence for this group of women. Although a significant difference emerged on the education variable for divorced women, it was not possible to comment on the direction of this relationship, and most others for divorced women, because Statistics Canada would not release the cross-tabulation to ensure respondent confidentiality. Although there was no difference in rates of violence by employment status for married women, unemployed separated women were about twice as likely and unemployed divorced women were 13 times as likely to report having experienced violence by their ex-partner compared to their employed counterparts. The presence of the ex-partner's children was associated with violence by ex-partners for both separated and divorced women. The presence of children in the household was not associated with violence for married women. Age was significantly associated with violence for all three groups of women, and Aboriginal status was not associated with violence for any of the groups of women. Jealousy was associated with violence for divorced and 
TABLE 2. One-year prevalence of violence by independent variables for separated, divorced, and married women (\%)

\begin{tabular}{|c|c|c|c|}
\hline Independent Variables & Separated & Divorced & Married \\
\hline \multicolumn{4}{|l|}{ Macrosystem } \\
\hline \multicolumn{4}{|l|}{ Ex- or partner's patriarchal dominance } \\
\hline Yes & 17.1 & 7.2 & 19.6 \\
\hline No & $5.9^{\star \star \star}$ & $1.6^{\star \star \star}$ & $0.9^{\star \star *}$ \\
\hline \multicolumn{4}{|l|}{ Microsystem } \\
\hline \multicolumn{4}{|l|}{ Education } \\
\hline High school or less & 6.7 & & 0.9 \\
\hline Some postsecondary & 7.6 & & 1.7 \\
\hline Community college diploma or certificate & 7.4 & & 0.7 \\
\hline University degree & 12.2 & $\dagger^{* *}$ & $1.4^{\star}$ \\
\hline \multicolumn{4}{|l|}{ Employment } \\
\hline Employed & 8.5 & 1.1 & 1.1 \\
\hline Unemployed & $16.1^{*}$ & $14.6^{\star \star \star}$ & 1.0 \\
\hline \multicolumn{4}{|l|}{ Children $<15$} \\
\hline Yes & 10.9 & & 1.3 \\
\hline No & $4.3^{\star \star}$ & $\dagger^{\star \star \star *}$ & 0.9 \\
\hline \multicolumn{4}{|l|}{ Ontogenic } \\
\hline \multicolumn{4}{|l|}{ Age } \\
\hline $15-34$ & & & 1.0 \\
\hline $35-54$ & & & 1.3 \\
\hline $55+$ & $\dagger^{\star * \star}$ & $\dagger^{* \star}$ & $0.7^{*}$ \\
\hline \multicolumn{4}{|l|}{ Aboriginal Status } \\
\hline \multicolumn{4}{|l|}{ Aboriginal } \\
\hline Non-Aboriginal & + & $\dagger$ & $\dagger$ \\
\hline \multicolumn{4}{|l|}{ Ex- or partner's jealousy } \\
\hline Yes & 10.6 & & 13.7 \\
\hline No & 6.9 & $\dagger^{\star \star \star}$ & $0.8^{\star \star \star}$ \\
\hline \multicolumn{4}{|l|}{ Ex-or partner's possessiveness } \\
\hline Yes & 14.4 & 5.9 & 10.5 \\
\hline No & $5.8^{* * *}$ & 1.5 & $0.8^{\star \star *}$ \\
\hline
\end{tabular}

$\dagger$ Statistics Canada would not release the cross-tabulation to ensure respondent confidentiality. ${ }^{\star} p \leq .10 .{ }^{\star \star} p<.05$. ${ }^{\star \star \star} p<.01$ ( $p$ values refer to Pearson chi-square tests of significance).

married women and possessiveness was associated with violence for separated and married women. There was also a tendency for the differences on these variables to be larger for married women. Separated women with a jealous or possessive ex-partner were about two to three times more likely to experience violence, divorced women with a possessive partner were about four times more likely to experience violence (although this difference did not reach statistical significance), and married women with 
husbands who behaved in a jealous or possessive manner were about 13 to 17 times more likely to report having experienced violence in the previous year.

\section{Multivariate Analysis: Logistic Regressions for Separated, Divorced, and Married Women}

Table 3 provides the results of the logistic regressions on the 1-year prevalence of violence for separated, divorced, and married women. In terms of the macrosystem variable of patriarchal dominance, the results showed that, controlling for all other variables in the models, having a partner who engaged in patriarchal domineering behavior through preventing access to the family income was associated with significantly increased odds of violence for all three groups of women ( $414 \%$ for separated women, $204 \%$ for divorced women, $668 \%$ for married women). As also shown in Table 3, a comparison of the odds ratios using $t$ tests showed that the impact of patriarchal domination on the odds for married women was significantly greater than was the impact of this variable on the odds of violence for divorced women.

At the microsystem level, education was associated with significant effects on the odds of violence for all three groups of women. Each unit of increase in years of education was associated with a $29 \%$ increase in odds of violence for separated women and a $13 \%$ increase in odds of violence for married women. For divorced women, on the other hand, each unit of increase in years of education was associated with a $42 \%$ decrease in their odds of violence. The results of the $t$ tests showed that the impact of education on the odds of violence was significantly different for each group of women.

In terms of employment status, there was no significant difference in odds of violence by whether or not the respondent was employed for either separated or married women. However, divorced women who were employed had $88 \%$ lower odds of violence than their unemployed counterparts. The results of the $t$ tests showed that the impact of employment status on the odds of violence for divorced women was statistically different from the impact of this variable for separated and married women.

Similar to employment status, the presence of children did not have a significant impact on the odds of violence for either separated or married women. For divorced women the presence of children was associated with significantly increased odds of violence. Divorced women with children of the ex-partner living in the household had $787 \%$ increased odds of violence compared to divorced women without children of the ex-partner in the household. The $t$ tests showed that the impact of the presence of 
children of the ex-partner on divorced women's odds of violence was significantly different from the impact of this variable on the odds of violence for separated and married women.

With respect to the ontogenic level, age was significantly negatively related to the odds of violence for separated and divorced women but not for married women. Each year of increase in age reduced separated women's odds of violence by $9 \%$ and divorced women's odds of violence by $8 \%$. The results of the $t$ tests showed that the impact of age was statistically similar for separated and divorced women and that the difference in the impact of age between these two groups of women and married women was statistically significant.

Aboriginal status did not have a significant impact on the odds of violence for any of the groups of women. Although the odds ratios for separated and married women were large and appeared to be substantively significant (75\% and $102 \%$, respectively), the results of the $t$ tests showed that the odds ratios were not significantly different across the three groups of women.

Although jealousy did not have a significant impact on the odds of violence for separated women, both divorced and married women with ex- or current partners who were jealous had significantly increased odds of violence. Divorced women with jealous ex-partners had $567 \%$ greater odds of violence and married women with jealous partners had $754 \%$ greater odds of violence than their counterparts without jealous partners. The results of the $t$ tests showed that the increased odds of violence for divorced and married women were significantly different from separated women's odds.

Jealousy was not linked to increased odds of violence for separated women, but possessiveness did have a significant impact on the odds of violence for separated women. Separated women with a possessive partner had $217 \%$ greater odds of violence than separated women without a possessive partner. Similarly, married women with a possessive partner had $246 \%$ greater odds of violence compared to their counterparts without a possessive partner. By contrast, possessiveness did not have a significant impact on the odds of violence for divorced women. The results of the $t$ tests showed that the odds ratios for separated and married women were statistically similar and these odds ratios were statistically different from the odds ratio for divorced women.

In terms of the variance explained by each model, an examination of the Nagelkerke pseudo $r^{2}$ suggested that the variables in the study explained the most variance for divorced women $(43 \%)$, followed by separated women $(27 \%)$ and married women $(15 \%)$. 


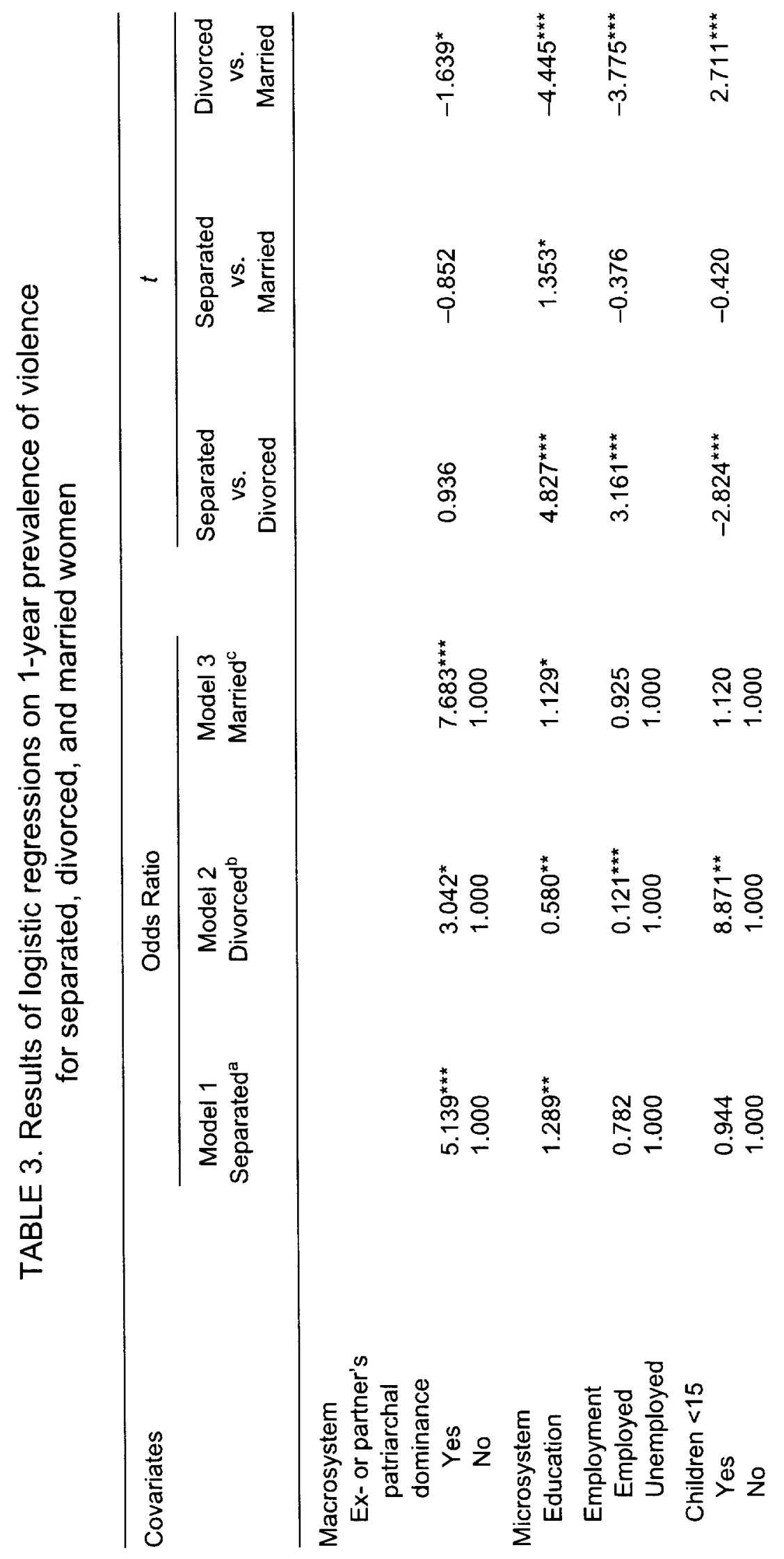




\begin{tabular}{|c|c|c|c|c|c|c|}
\hline \multicolumn{7}{|l|}{ Ontogenic } \\
\hline Age & $0.905^{\star \star \star}$ & $0.923^{*}$ & 0.985 & -0.514 & $-4.011^{\star \star \star}$ & $-1.848^{\star \star}$ \\
\hline \multicolumn{7}{|l|}{ Aboriginal status } \\
\hline Aboriginal & 1.754 & 0.979 & 2.024 & 0.476 & -0.160 & -0.602 \\
\hline Non-Aboriginal & 1.000 & 1.000 & 1.000 & & & \\
\hline \multicolumn{7}{|l|}{ Ex- or partner's jealousy } \\
\hline Yes & 0.543 & $6.672^{\star \star}$ & $8.540^{\star \star \star}$ & $-3.429^{\star \star \star}$ & $-5.339^{\star * \star}$ & -0.372 \\
\hline No & 1.000 & 1.000 & 1.000 & & & \\
\hline \multicolumn{7}{|l|}{$\begin{array}{l}\text { Ex- or partner's } \\
\text { possessiveness }\end{array}$} \\
\hline Yes & $3.170^{\star}$ & 0.508 & $3.460^{\star \star \star}$ & $2.705^{\star \star \star}$ & -0.170 & $-3.161^{* * *}$ \\
\hline No & 1.000 & 1.000 & 1.000 & & & \\
\hline Constant & 0.119 & 260.858 & $0.002^{\star \star \star}$ & & & \\
\hline-2 Log likelihood & 181 & 87 & 548 & & & \\
\hline$\chi^{2}$ & $51^{\star \star \star}$ & $58^{\star \star \star}$ & $93^{* \star \star}$ & & & \\
\hline Nagelkerke Pseudo $R^{2}$ & 0.269 & 0.430 & 0.153 & & & \\
\hline
\end{tabular}

${ }^{a} n=416 .{ }^{b} n=598 .{ }^{c} n=5,442$.

${ }^{\star} p \leq .10 .{ }^{\star \star} p<.05 .{ }^{\star \star \star} p<.01$. 


\section{DISCUSSION}

Consistent with past Canadian (Brownridge et al., 2008; Johnson, 1990; Kennedy \& Dutton, 1989) and American (Bachman \& Saltzman, 1995; Gaquin, 1977/1978; Kershner, Long, \& Anderson, 2001) research, the results of this study showed that separated and divorced women reported an elevated risk for violence compared to married women. Separated women had three times the prevalence of violence compared to divorced women and seven times the prevalence compared to married women. Divorced women had two times the prevalence of violence compared to married women in the year prior to the survey.

A nested ecological framework was used to examine the impact of available risk markers on each group of women in an effort to help identify whether there were differing dynamics of risk for the three marital status groups. At the macrosystem level the results showed that a high percentage of separated and divorced women's ex-partners behaved in a patriarchal dominating manner compared to married women's husbands. Although patriarchal dominance was associated with violence for all three groups of women in both the descriptive and multivariate analyses, the multivariate analysis showed that patriarchal dominance was most strongly associated with significantly increased odds of violence for married women. Thus, whereas ex-partners of separated and divorced women were more likely to engage in patriarchal dominating behavior, such behavior tended to be a stronger predictor of marital violence. Results from this study were consistent with Brownridge et al. (2008), with the exception that the latter study found patriarchal dominance to be a significant predictor only of marital violence. Hence, the available evidence suggests that patriarchal domineering behavior is a better predictor of marital than postseparation violence.

In terms of the microsystem level, separated, divorced, and married women possessed similar education levels. The multivariate analysis showed that education was positively linked to violence for separated and married women and negatively related to violence for divorced women. This finding was contrary to that of Brownridge et al. (2008), in which education was not a significant predictor of violence for any of the groups of women. Although separated and divorced women tended to be more likely to be employed, and employment was related to violence, the relationship was the opposite of what would be predicted based on the application of the nested ecological framework. According to the bivariate results, unemployed separated and divorced women were more likely to 
report violence. Dependence rather than independence, as measured by unemployment, was a significant predictor of violence against divorced women in the multivariate analysis. This was consistent with past research (Brownridge et al., 2008). So, although expressions of independence may predict violence against separated and married women in terms of education resources, why would the opposite be the case for divorced women in terms of both education and employment resources? One possible explanation may be that divorced men's resentment over having to support their former wife leads them to retaliate with violence. Perhaps with the passage of time these men have accepted their ex-wives' expression of independence by virtue of them leaving, and now the main concern is having to support the women who betrayed them by leaving. Hence, retaliation may be a stronger motivation for violence against divorced women than efforts to reassert control resulting from these women's expressions of their independence. In this way it is possible to understand how being more independent through the possession of more education and employment resources would predict a lower likelihood of violence for divorced women.

Separated women were the most likely to have children of the union residing in the household and the descriptive analysis showed that this variable was positively associated with violence for separated and divorced women. However, the multivariate analysis revealed that the presence of children of the union significantly impacted the odds of violence only for divorced women. Although Brownridge et al. (2008) found that the presence of children was not a significant predictor of violence for any of the groups of women, this study employed a different measure that was not available in the 1999 GSS that allowed a focus on only children of the union for separated and divorced women. It is possible that focusing only on children of the union for ex-partners increased the sensitivity of this variable in this study. These results suggested the possibility that issues related to children of the union, such as support, access, and custody arrangements, may play a role in some divorced women's experiences of violence by their ex-partners.

With respect to the ontogenic level, separated women were younger on average than divorced and married women and this variable was associated with violence for all three groups of women at the bivariate level. At the multivariate level, however, the results revealed that young age was a significant risk factor for violence only among separated and divorced women. These results were generally consistent with past research (Brownridge et al., 2008). 
Aboriginal status was not significantly associated with violence for any of the three groups of women. This was contrary to Brownridge et al. (2008) who found that Aboriginal status was a significant predictor of violence for separated and married women. However, these researchers noted that caution needed to be exercised in extrapolating from their results due to the small subsamples of Aboriginal separated $(n=12)$ and divorced $(n=8)$ women. Although the subsamples for separated and divorced women were slightly larger in this study (see Table 1), the same caveat is warranted. With that in mind, the most that can be said is that findings are mixed in terms of the relationship between Aboriginal status and violence against separated women. The findings are nevertheless consistent for divorced women. It is possible that divorce may not be a significant risk factor for violence against Aboriginal women because Aboriginal persons in Canada tend to avoid formal divorce (Frideres, 2001).

With respect to sexual proprietariness, the results showed that a high percentage of separated and divorced women's ex-partners behaved in a sexually proprietary manner, through jealousy or possessiveness, compared to married women's husbands. There was some variability in the impact of jealousy and possessiveness for separated and divorced women. Jealousy did not have a significant impact on the odds of violence for separated women but tended to be related to increased odds of violence for divorced women; possessiveness did not have a significant impact on the odds of violence for divorced women, but had a significant impact on the odds of violence for separated women. Both jealousy and possessiveness were consistently related to increased odds of violence for married women. Hence, although ex-partners of separated and divorced women were more likely to engage in sexually proprietary behavior, such behavior appeared to be a stronger and more consistent predictor of violence against married women. The study by Brownridge et al. (2008) found an even stronger indication of this, with the sexual proprietariness variables significantly predicting violence only against married women. Thus, available evidence suggests that behaviors that reflect concern over usurpation by sexual rivals are better predictors of marital than postseparation violence.

In addition to the small number of separated and divorced Aboriginal women in the sample, there were some other noteworthy limitations of this study. First, the GSS is limited as a result of being a "crime survey." DeKeseredy, Rogness, and Schwartz (2004) criticized such studies for creating "a set of 'demand characteristics' and unless female respondents 
clearly label their current or former partners' abusive acts as criminal in their own mind (and many women do not do so), they tend not to report them" (p. 680). Hence, there may be a problem of underreporting violence in this study. Although this may have affected overall prevalence rates for each group of women in the study, the differences in rates of violence reported by separated, divorced, and married women were consistent with what was expected based on past research and the data were useful for examining the influence of risk markers on each group separately. A second limitation concerned the restriction to risk markers that were available in the data. Several risk markers applicable to separated and divorced women's ecology could not be tested, which at least partially accounted for explaining at best less than half of the variance in violence. Although the levels of explained variance were within or beyond the $10 \%$ to $20 \%$ range commonly found in the field of family violence (O'Neil \& Harway, 1999), the availability of additional risk markers that had previously been identified as being associated with postseparation violence (cf. Brownridge, 2006) would likely have increased the explanatory power of the models. Third, the study was limited to available measures of risk markers. For example, education and employment status are limited proxies of women's independence (Kaukinen, 2004; MacMillan \& Gartner, 1999). Finally, like most of the research on nonlethal postseparation violence (Brownridge, 2006), the analysis could not distinguish between violence that occurred while the relationship was intact and violence that occurred after the separation began. Although the intent of most of the research in the area is to examine violence that began subsequent to the moment of physical separation, it is also true that most research has been unable to make this distinction. Given that it was also not possible to make these distinctions in this analysis, a 1-year time frame for the violence variable was used to attenuate this problem by maximizing the likelihood that the violence reported was experienced at the respondent's current marital status. The dependent variable nevertheless confounded violence that occurred pre- and postseparation and this limitation should be borne in mind when extrapolating from the results. Despite this inability to specify exactly when violence occurred, the results for separated and divorced women were sufficiently distinct from married women to suggest some unique dynamics in the risk for violence against women who were separated or divorced at the time of the study.

The variables included in the study explained a sizable portion of the variance for divorced, a moderate amount for separated, and a lesser amount for married women. This lent further credence to the notion that 
there were some differing dynamics in violence against separated, divorced, and married women. Overall, young age is an important variable for understanding violence against separated and divorced women in Canada. Unemployment and the presence of children of the union appeared to be particularly important predictors for divorced women. For married women patriarchal domination and sexual proprietariness were particularly strong predictors of violence. This was not to say that these patriarchal domination and sexual proprietariness variables lacked importance for understanding separated and divorced women's reports of violence by their former husbands. Indeed, they were much more likely to report that their former husbands engaged in such behaviors compared to married women's reports of their husband's behavior and a significant percentage of these men were violent. However, patriarchal domination, sexual jealousy, and possessiveness tended to be less powerful predictors of violence against separated and divorced women because, as shown in the descriptive analysis (see Table 2), there was a tendency for a much larger percentage of these women's ex-partners who did not engage in such behaviors to also be violent compared to married women's husbands who did not engage in such behaviors. This is consistent with the notion that there were other risk factors and motivations that were unique to ex-partners that contributed to violence against separated and divorced women.

Motivations that may be particularly relevant to postseparation violence include restoration, reconciliation, and retaliation (cf. Brownridge, 2006). Men who are violent postseparation may be attempting to restore power and control over their ex-partner that they have lost through the separation. Although this appeared likely to have been the case for some of the respondents in this study, the high proportion of separated and divorced women who were victimized despite having partners who were not domineering or sexually proprietary suggested that the motives of reconciliation and retaliation also played a role in a number of cases. Some of these men likely used violence in an attempt to force reconciliation. This may be particularly relevant to separated men who are perhaps more likely to be hopeful for reconciliation given that the divorce is not yet finalized. Other men likely used violence in retaliation for the feelings of betrayal, abandonment, and rage resulting from the separation and circumstances accompanying the divorce. In the latter regard, retaliation may be particularly relevant to divorced men based on the finding of this study that issues of dependence appeared to be strong predictors of violence against divorced women. Given the limitations of this study already 
outlined, future research is warranted that is specifically designed to uncover the potentially differing dynamics of violence, and the contexts that give rise to them, for separated and divorced women. An understanding of these dynamics would have important implications for the prevention of postseparation violence by, for example, assisting service providers to target their prevention efforts depending on whether a given client is separated or divorced.

\section{NOTES}

1. Although the research and analysis are based on data from Statistics Canada, the opinions expressed do not represent the views of Statistics Canada.

2. Ex-partners included men from either a marriage or a common-law relationship. Data restrictions did not allow disaggregation of ex-partners by whether they had been living in a marital or common-law relationship.

3. Women in same-sex relationships were excluded from the analyses.

4. Because the data were not drawn from a simple random sample, it was necessary to weight the data so that the population was adequately represented. In an analysis of a subsample of the data, the weights provided with the data must be rescaled in a manner that preserves the variability of the original weights but has an average value of one. This was accomplished by first calculating the average weight for those respondents in the analysis and then dividing each respondent's weight by this average. The resulting weighting factor was used in all of the analyses in this study.

5. It must be noted that this was an individual-level indicator of patriarchal domination between a couple rather than a measure of patriarchal culture. For further elaboration of this conceptualization of patriarchal domination, readers may wish to refer to Brownridge (2002).

\section{REFERENCES}

Anderson, D. K., \& Saunders, D. G. (2003). Leaving an abusive partner: An empirical review of predictors, the process of leaving, and psychological well-being. Trauma, Violence and Abuse, 4, 163-191.

Bachman, R., \& Saltzman, L. E. (1995). Violence against women: Estimates from the redesigned survey (No. NCJ-154348). Rockville, MD: U.S. Department of Justice Bureau of Justice Statistics.

Blood, R. O., \& Wolfe, D. M. (1960). Husband and wives: The dynamics of married living. Glencoe, IL: Free Press.

Brownridge, D. A. (2002). Cultural variation in male partner violence against women: A comparison of Québec with the rest of Canada. Violence Against Women, 8(1), 87-115.

Brownridge, D. A. (2003). Male partner violence against Aboriginal women in Canada: An empirical analysis. Journal of Interpersonal Violence, 18(1), 65-83. 
Brownridge, D. A. (2006). Violence against women post-separation. Aggression and Violent Behavior, 11, 514-530.

Brownridge, D. A., Chan, K. L., Hiebert-Murphy, D., Ristock, J., Tiwari, A., Leung, W.-C., et al. (2008). The elevated risk for non-lethal post-separation violence in Canada: A comparison of separated, divorced, and married women. Journal of Interpersonal Violence, 23(1), 117-135.

Brownridge, D. A., \& Halli, S. S. (2002). Understanding male partner violence against cohabiting and married women: An empirical investigation with a synthesized model. Journal of Family Violence, 17, 341-361.

DeKeseredy, W. S., Rogness, M., \& Schwartz, M. D. (2004). Separation/divorce sexual assault: The current state of social scientific knowledge. Aggression and Violent Behavior, 9, 675-691.

Dutton, D. G., \& Painter, S. (1993). Emotional attachments in abusive relationships: A test of traumatic bonding theory. Violence and Victims, 8, 105-120.

Fleury, R. E., Sullivan, C. M., \& Bybee, D. I. (2000). When ending the relationship does not end the violence: Women's experiences of violence by former partners. Violence Against Women, 6, 1363-1383.

Frideres, J. S. (2001). Aboriginal peoples in Canada: Contemporary conflicts (6th ed.). Toronto: Prentice Hall.

Gaquin, D. A. (1977/1978). Spouse abuse: Data from the national crime survey. Victimology, $2,632-643$.

Goode, W. J. (1971). Force and violence in the family. Journal of Marriage and the Family, $33,624-636$.

Hardesty, J. L. (2002). Separation assault in the context of postdivorce parenting. Violence Against Women, 8, 597-625.

Hewitt, B., Baxter, J., \& Western, M. (2005). Marriage breakdown in Australia: The social correlates of separation and divorce. Journal of Sociology, 41, 163-183.

Hotton, T. (2001). Spousal violence after marital separation, Juristat, 21, 1-19.

Johnson, H. (1990). Wife abuse. In C. McKie \& K. Thompson (Eds.), Canadian social trends (pp. 173-176). Toronto: Thompson.

Johnson, H. (1996). Dangerous domains: Violence against women in Canada. Scarborough, ON: Nelson Canada.

Johnson, H., \& Hotton, T. (2003). Losing control: Homicide risk in estranged and intact intimate relationships. Homicide Studies, 7(1), 58-84.

Kaukinen, C. (2004). Status compatibility, physical violence, and emotional abuse in intimate relationships. Journal of Marriage and Family, 66, 452-471.

Kennedy, L. W., \& Dutton, D. G. (1989). The incidence of wife assault in Alberta. Canadian Journal of Behavioural Science, 21(1), 41-54.

Kershner, M., Long, D., \& Anderson, J. E. (2001). Abuse against women in rural Minnesota. Public Health Nursing, 15, 422-431.

Kurz, D. (1996). Separation, divorce and woman abuse. Violence Against Women, 2, 69-81.

MacMillan, R., \& Gartner, R. (1999). When she brings home the bacon: Labor-force participation and the risk of spousal violence against women. Journal of Marriage and the Family, 61, 947-958. 
McMurray, A. M. (1997). Violence against ex-wives: Anger and advocacy. Health Care for Women International, 18, 543-556.

McMurray, A. M., Froyland, I. D., Bell, D. G., \& Curnow, D. J. (2000). Post-separation violence: The male perspective. Journal of Family Studies, 6, 89-105.

O'Neil, J. M., \& Harway, M. (1999). Revised multivariate model explaining men's risk factors for violence against women: Theoretical propositions, new hypotheses, and proactive recommendations. In M. Harway \& J. M. O'Neil (Eds.), What causes men's violence against women? (pp. 207-241). Thousand Oaks, CA: Sage.

Rasche, C. E. (1993). "Given" reasons for violence in intimate relationships. In A. V. Wilson (Ed.), Homicide: The victim/offender connection (pp. 75-100). Cincinnati, OH: Anderson.

Spiwak, R., \& Brownridge, D. A. (2005). Separated women's risk for violence: An analysis of the Canadian situation. Journal of Divorce and Remarriage, 43(3/4), 105-118.

Statistics Canada. (2004). Divorces. The Daily(May 4), 1-5.

Statistics Canada. (2005). General Social Survey Cycle 18: Victimization (2004): User's guide to the public use microdata file. Ottawa, ON: Minister of Industry.

Straus, M. A. (1979). Measuring intrafamily conflict and violence: The Conflict Tactics (CT) scales. Journal of Marriage and the Family, 41, 75-88.

Wilson, M., \& Daly, M. (1993). Spousal homicide risk and estrangement. Violence and Victims, 8(1), 3-16.

Wilson, M., \& Daly, M. (1998). Lethal and nonlethal violence against wives and the evolutionary psychology of male sexual proprietariness. In R. E. Dobash \& R. P. Dobash (Eds.), Rethinking violence against women (pp. 224-230). Thousand Oaks, CA: Sage.

Yllö, K. A., \& Straus, M. A. (1990). Patriarchy and violence against wives: The impact of structural and normative factors. In M. A. Straus \& R. J. Gelles (Eds.), Physical violence in American families: Risk factors and adaptations to violence in 8,145 families (pp. 383-399). New Brunswick, NJ: Transaction. 